\title{
Godsdienstige perspektiewe op mens-dier interaksie
}

\author{
M van Heerden \\ Departement Maatskaplike Werk \\ Universiteit van Pretoria
}

\begin{abstract}
Religious perspectives on human-animal interaction

The relationship between humans and animals can be influenced by religious belief. Regardless of the diversity of religions, kindness to all of God's creatures seems to be a central concept. Theologians concerned with animal ethics currently emphasize an ecosystem approach with the focus on reverence for life and restricting harm to and suffering of all forms of life. Today many Christians experience an enriching relationship with animals. Although church leaders played an important role in the history of animal welfare, the human-animal bond is not an issue which receives much attention in the Christian church today. The role of theology in a multidisciplinary approach towards the enhancement of positive human-animal interaction, by means of research, education and congregational ministry is advocated.
\end{abstract}

\section{INLEIDING}

Die geskiedenis van die mens-dierband word gekenmerk deur kontradiksies: Diere is as gode vereer maar ook as "bose geeste" uitgeskel, met 'n siel verbind maar ook as verstandlose "masjiene" geag, as objekte van vrees geoordeel maar ook met liefde as gesinslede ingeneem (Manning \& Serpell 1994:xi). Hierdie diversiteit in rolvervulling het met verloop van tyd ontstaan deur ' $n$ dinamiese proses van domestisering om aan te pas by die veranderende behoeftes van sowel mense as diere. Alhoewel die verhouding tussen mens en dier al soveel milleniums bestaan en die proses soveel veranderings 
ondergaan het, het die laaste eeu die mees ingrypende veranderings en herdefiniëring van mens-dier interaksie as studieveld tot gevolg gehad. Die idee dat diere, net soos mense, gevoelens en emosie besit het in die Westerse kultuur sy beslag. Teen die laat sewentigerjare is die konsep van dierewaarneming- en gevoelsvermoë algemeen aanvaar en net deur 'n klein groepie fundamentaliste bevraagteken (vgl Fogle 1999:234), terwyl dit vandag wetenskaplik bewys kan word (vgl Plous 1993:27; Rogers 1995:101; Odendaal \& Meintjes 1999:1-10).

Geloofsoortuigings vorm 'n integrale deel van menswees en beïnvloed tot 'n groot mate die onderskeie groeperinge se houding en gedrag teenoor diere. Ten spyte van die diversiteit tussen groepe, is daar tog 'n basiese ooreenkoms in hulle sienings dat alle skepsels op aarde respek verdien. In 'n publikasie van die Humane Education Trust (Animal Voice 2000:1, 8), word Albert Schweitzer en Sir Wilfred Grenfell aangehaal waar hulle sê dat 'n mens se geloof min waarde het tensy selfs die mees oënskynlik nietige skepsels daarby baat, en dat welwillendheid teenoor ál God se skepsels noodsaaklik is as vrede en geregtigheid nagestreef wil word. Die toepaslikheid van mens-dier interaksie as studieveld vir die teologie lê dus veral op die vlak van die etiek. Linzey (1994:viii) stel dit dat op hierdie gebied, die tyd "oorryp" is vir "... a theological change-of-heart leading to ethical re-evaluation."

\section{DIE INTRINSIEKE WAARDE VAN DIERE}

Daar bestaan vandag 'n groter bewustheid van die waarde wat aan diere geheg word as skepsels van God en die regte wat daardeur geïmpliseer word. Die wegbeweeg van 'n direkte, letterlike interpretasie van die Bybel het volgens Swabe (1999:8) meegebring dat mense al meer die siening begin huldig dat die mens die versorgers eerder as die heersers van die natuurlike wêreld is. Hierdie "nuutgevonde" Christelike konsep het volgens haar daartoe gelei dat 'n houding van respek, omgee en verantwoordelikheid teenoor diere ontwikkel het. Turner (1996:25) stem hiermee saam en stel dit dat daar tans konsensus onder Christen teoloë bestaan dat die waarde oordeel dat álle lewe waarde het en dus beskerm moet word teen pyn en lyding, sy oorsprong in die Bybel het. Hierdie nuwe konsensus verbied egter nie the gebruik, doodmaak of verbruik van diere nie, maar verwag dat dit binne perke en binne die konteks van respek sal geskied. 
Wat in praktyk met 'n "nuwe konsensus" bedoel word is egter onseker. Die "gebruik", "doodmaak" en "verbruik" kan ook die doodmaak van diere vir sport, plesier of navorsingsdoeleindes impliseer. Dit is ook nie seker wat met "binne perke" bedoel word nie. Wie stel die grense? Verdedigers van die nuttigheidswaarde van diere maak daarop aanspraak dat hulle steeds respek het vir die diere en dat hulle metodes van doodmaak, in hulle eie definisie daarvan, nie wreed is nie. 'n Volgende vraag is of dit werklik 'n "nuwe" konsensus is? Respek vir diere as volledig deel van die skepping word in sowel die Ou Testament as Nuwe Testament na verwys (vgl Frear 1993:5-7). Clark (1997:6) wat homself beskou as Christen filosoof sê dat geeneen wat die Bybel lees enigsins kan twyfel dat die skrywers daarvan 'n diepe bewustheid van die natuurlike wêreld, as volledig deel van die skepping, gehad het nie. Natuur word gesien as die niemenslike Godgeskape omgewing wat beheer word deur kragte onbekend aan die mens: “... a world continually offering embodied images of the spiritual values they pursued." Díe Bybelse tradisie erken dat ons (menslike) kragte nie anders of beter is as díe van ander wesens nie, en dat “... the Lord stands over all”. Hierdie blyk dus nie 'n nuwe konsensus te wees nie, maar wel 'n refleksie van hoe respek vir die skepping, en diere as volledig deel daarvan, uitgelewer is aan menslike interpretasies van die tyd.

'n Ekosistemiese benadering tot die skepping en die waarde van alles en almal daarin behoort volgens Clark (1997:79-80) die uitgangspunt van die gelowige te wees. Vryheid berus op die waarde wat God plaas op elke individu as unieke uitbeelding tot sy eer tot so 'n mate dat "... any despotism, however benevolent in purpose, must issue in a decline of valuable diversity." Elkeen van ons het dus 'n diepliggende en kardinale belang by die waarde van ons mede-aardbewoners en die ekosisteme waarbinne ons 'n leefruimte deel. Clark (1997:96) motiveer dit verder deur te sê dat die wêreld nie vir ons mense alleen gemaak is nie. Die goeie is daarin geleë om te sorg en om te gee vir alles in die skepping, en die verkeerde is om pyn en ellende te veroorsaak aan hulle wie aan ons uitgelewer is deur hulle soos ons eiendom, in plaas van skepsels in eie reg, te behandel. Dit is dus nie net rasionaliteit wat respek verdien nie, maar ook die individuele waardigheid van elke subjek-van-lewe (vgl Clark 1997:102-103). Op die argument dat die mens 'n meer superieure skepsel is en daarom hoër gereken behoort te word, reageer hy soos volg: "Our 'superiority', insofar as that is real, rests not upon our self-claimed 
right always to have more than other creatures do (which is what our modern humanism amounts to), but on the possibility that we may (and the corresponding duty that we should) allow our fellow creatures their part of the action" (Clark 1997:168). Ons behoort dus te leef by die reëls wat deur God daargestel is, naamlik om nie méér vir onsself en die "eie" aan ons in te palm as wat ons "ander" gun en wat hulle toekom nie.

\section{VERSKILLENDE GODSDIENSTIGE OORTUIGINGS}

Tydens die Agtste Internasionale Konferensie oor Mens-Dier interaksie in Praag (1998), is ' $n$ spesiale sessie afgestaan aan die mens-dierverhouding en verskillende godsdienste van die wêreld. Figle (1998:1-12) het in sy referaat 'n onderskeid getref tussen uitgangspunte en filosofieë van Indiese oorsprong (Hindoeïsme, Jaïnisme, Boeddhisme), Chinese oorsprong (Konfusianisme, Taoisme, Neokonfusianisme), Grieks-Romeinse oorspong (denkrigtings beïnvloed deur Aristoteles, die Stoa en die Romeinse reg) en die monoteïstiese godsdienste (Judaisme, Christenskap en Islam): Die sentrale konsep van die Hindoeïsme, wat sowat 2500 jaar terugdateer, is dat verhoudings tussen alle skepsels gekenmerk moet word deur nie-wreedheid. In moderne Hindoeïsme is die offer van diere die uitsondering en gaan gepaard met 'n ritueel van apologieë teenoor die dier. Die neiging is ook al meer om simboliese offers te maak as substituut vir diere offers. Die Jaïnisme plaas 'n verbod op enige vorm van doodmaak, selfs van die kleinste insek. Ook vir die Boeddhis is die beginsel van nie-wreedheid die eerste wet en word barmhartigheid en simpatie teenoor diere hierby ingesluit. Selfs beroepe wat in konflik met hierdie wet is, byvoorbeeld wapenhandel, handel met diere, en die teel van diere om te slag, moet vermy word. Die Boeddhis se gedrag teenoor diere moet gerig wees op die bevordering van lewenskwaliteit vir die hele samelewing en nie net ter wille van sy eie lewensfere nie (vgl Hung 1998:1-6; McDaniel, 1993:85; Palmer \& Breuilly 1996:39-44).

Figle (1998:1-2) gaan voort deur te sê dat die klem vir die Konfusianiste op die regte verhouding met die natuur, en om in harmonie met alles en almal te leef, lê. Taoisme interpreteer hierdie verhouding verder en vermy enige menslike negatiewe inmenging in die natuur. Beskerming moet nie net aan diere gebied word nie, maar ook aan riviere, plante, berge ensovoorts. Neokonfusianisme stem hiermee ooreen en bepleit barmhartigheid teenoor mense, diere, plante asook lewelose dinge. Die denkrigting van 
Aristoteles het waarskynlik die grootste invloed op die westerse samelewing met betrekking tot die verhouding tussen mens en dier gehad (vgl Cohen 1994:61). Aristoteles beskou die mens as die sentrale punt in die skepping en heg slegs 'n nuttigheidswaarde aan diere. Hierdie uitgangspunt word verder gevoer in die Hellinistiese periode, en spesifiek die Stoïsisme, wat van die standpunt uitgaan dat die natuur as geheel aan die mens behoort en daarom deur die mens gebruik kan word. In die antieke Romeinse tyd is diere as objekte gesien met geen regte nie. Interessant dat slawe onder dieselfde wet as nie-persone gesien is, ook met geen regte nie (vgl Clutton-Brock 1994:31). As in ag geneem word dat in die antieke tye daar nie 'n onderskeid gemaak is tussen godsdiens, regte, ekonomie en familielewe nie, kan die implikasies wat hierdie wette op die welsyn van diere gehad het, ingesien word.

Die moderne Islamitiese godsdiens word oor die algemeen gekenmerk deur 'n positiewe houding teenoor diere. Aydin (1998:1-16) motiveer hierdie stelling deur aanhalings uit die Koran en uitsprake deur die profeet Muhammed. Mense word beskou as slegs een van baie families van lewende wesens in die gemeenskap. Daar word nie onderskeid getref tussen die waarde wat die een bo die ander voor die Opperwese het nie. Van die hoofstukke in die Koran het selfs dierename byvoorbeeld; Die Bees (al-an'âm), Die By (al-nahl), Die Mier (al-naml), Die Spinnekop (al-ankabût) en Die Olifant (al-fil). Allah gebruik voorbeelde van dieregedrag om die verwagtings wat aan mense gestel word, uit te beeld en dus as rolmodelle te dien. Die profeet Muhammed het veral uitsprake gelewer ten opsigte van barmhartigheid teenoor diere en dat dit deur Allah beloon sal word en dat dit selfs sal vergoed vir ander sondes, maar ook dat wreedheid teenoor diere gestraf sal word.

Vir die Jodendom, wat die Ou Testament as vertrekpunt gebruik, bestaan daar 'n simbiotiese verhouding tussen mense en diere. Enkele voorbeelde hiervan word na verwys in Genesis 49:5-7; Deuteronomium 5:14, 22:10; 25:4; Spreuke 12:10. Respek vir diere en veroordeling van wreedheid teenoor diere word hier beklemtoon. Kritiek op die offer en jag van diere word ook dikwels in die rabbynse literatuur teëgekom (Figle 1998:8), alhoewel dit tog aanvaarde praktyk in die tempels was. Ten spyte dus van die nuttigheidsrol wat diere gespeel het, asook die interpretasie dat een van die skeppingsverhale die mens se mag oor die dier uitbeeld, word diere as volledig deel van 
God se skepping gesien en moet dienooreenkomstig behandel word (vgl Jones 1992:210; Maehle 1994:83). Die skepping behoort, volgens Watson (1998:1) nie as 'n eenmalige gebeurtenis gesien te word nie, maar as 'n deurlopende proses. 'n Proses dui op 'n bepaalde dinamika wat verandering insluit. Religieuse interpretasies ten opsigte van mens-dier interaksie is, net soos die interpretasies met betrekking tot ander ver-houdings, deel van hierdie veranderingsproses.

\section{CHRISTELIKE BESKOUIINGS TEENOOR DIERE}

Die houding van die Christendom teenoor diere word beïnvloed deur verskeie tradisies. Enersyds word die Ou Testament deur die vroeë Christene as vertrekpunt gebruik wat dus die sentimente van die Jode reflekteer, maar die Hellinisme en later Romeinse tradisies speel ook 'n belangrike rol (vgl Ruether 1993:17). Die Nuwe Testament word gekenmerk deur die werk en woorde van Jesus Christus, wat as die basiese beginsels en waardes van die Christendom behoort te dien. Jesus se empatie en verhouding tot mens en dier blyk voorts uit beskrywings in die vier evangelies. Tog wil dit voorkom of hierdie nie as rolmodel vir die Christelike kerk gedien het nie! Die eerste 1800 jaar van die Christelike kerk het die klem laat val op die nuttigheidsrol van diere, suiwer tot voordeel van die mens, en die mens se dominansie oor die skepping. Hierdie siening is in stand gehou deur die hervorming gedurende die $15^{\mathrm{e}}, 16^{\mathrm{e}}$ en $17^{\mathrm{e}}$ eeu. In hierdie tyd het veral geselskapsdiere (troeteldiere) daaronder gelei omdat sommige van hulle geassosiëer was met "boosheid" en "sonde" (vgl Cohen 1994:67-68; Maehle 1994:85.)

In die $20^{\mathrm{e}}$ eeu is daar steeds ' $\mathrm{n}$ teenstrydigheid tussen die houding van Christene en dié van Christelike instellings teenoor diere. McDaniel (1993:75) maak hieroor die volgende opmerking: "Many Christians find themselves enriched by a sense of kinship with animals and the Earth, and yet unable to experience Christianity, at least in its institutional and doctrinal expressions, as supportive of such kinship." Deur Christus is die goeie nuus na die wêreld gebring, maar was dit goeie nuus net vir mense of vir alles en almal in die skepping? Hauerwas \& Berkman (1993:73) sê dat die goeie nuus daar is vir almal en dat God ons oproep om in dankbaarheid die weg te loop van die offer van Christus en dat die goeie nuus vir ander diere is dat Christene nie nodig het om diere deel te maak van offers wat geen doel het in God se koninkryk nie. Die vraag wat by 
Christene opkom wanneer hieroor geredeneer word is of diere dan 'n siel het? In die boek Prediker (3:19) sê die skrywer dat die mens nie beter daaraan toe as die dier is nie, en dat ons nie weet of die asem van die mens opstyg boontoe en of die asem van die dier afgaan onder toe nie (vgl Pred 3:21). Die vraag kan egter eerder gevra word of die teenwoordigheid van 'n "siel", jou waarde bepaal voor God?

Teenstrydighede bestaan dus lank reeds in teologiese uitgangspunte ten opsigte van geloof en diere. Die heidense godsdienste, wat gekenmerk was deur ' $n$ veelgodedom, het dikwels diere as deel van hulle godsdiensbeoefening aanbid, maar ook weer onderhewig gestel aan veroordeling en straf onder die Romeinse reg. Die positiewe rol van die Christelike Kerk ten opsigte van die welsyn van diere kom wel in die volgende voorbeelde na vore (vgl French 1993:35-36; Hume 1980:57-58; Maehle 1994:85-86; Newby 1997:Hfst 4; Watson 1998:1-11).

St Francis van Assissi en St Anthony was van die eerste kerkleiers wat hulle positief uitgespreek het vir die waarde van diere, God se liefde vir diere, die belangrikheid van die mens- dierband en die mens se verantwoordelikheid teenoor diere. In 1776 het Eerwaarde Humphry Primatt 'n teologiese studie gepubliseer waarin die Christen se verantwoordelikheid teenoor diere uitgespel word. In 1817 lewer Schopenhauer kritiek uit op die Christendom en sê dat "the morality of Christianity has no consideration for animals - a defect that is better admitted than perpetuated" (vgl Watson 1998:6). In 1824 word die Dierebeskermingsvereniging onder leiding van 'n Anglikaanse priester gestig. 'n Voormalige Aartsbiskop van Canterbury, Robert Runcie, verwerp die instrumentalistiese en nuttigheidswaarde van diere en lewer die uitspraak dat God se skepping alleen erken kan word in die interaktiewe verhouding tussen die skepsels van God. Tydens die 1998 Lambeth konferensie van die Anglikaanse kerk is vier sleutel resolusies, waarin die interaksie tussen en verantwoordelikheid van die mens teenoor die natuur en alles wat deur God geskep is, en God se verlossing deur Christus vir alles en almal uitgespel is, aanvaar.

Resolusies deur onderskeidelik die Anglikaanse Kerk, General Assembly of the Church of Scotland, Presbiteriaanse Kerk en Metodiste Kerk is reeds in die eerste helfte van die $20^{\mathrm{e}}$ eeu met betrekking tot die verantwoordelikheid vir die welsyn van diere aanvaar. 


\section{DIE REGTE VERHOUDING MET DIERE}

Die regte van diere word al vir eeue bepleit en gedebatteer vanuit verskillende dissiplines. Die vraag ontstaan waarom Christene, ten spyte van beginsels van liefde en respek, nie in die verlede meer aktief tot die debat toegetree het nie. Jung (1993:47) meen dat vanuit 'n Christelike perspektief eerder van 'n regte verhouding met diere gepraat moet word as van diereregte, omdat die verhouding die kern van die saak is. Nietemin begin diereregte aktiviste van die $20^{\mathrm{e}}$ eeu 'n verband trek tussen godsdiens en diereregte. Vir Linzey (1994:ix) lê die verband daarin dat die teologie die baan weg waarop die regte van diere verlos kan word van sy huidige "philosophical straightjacket". Jones (1992:220) is van mening dat die regte waaroor die mens en dier beskik grootliks verskil omdat die mens oor geestelike en morele kwaliteite beskik wat op abstrakte denke berus. Die regte waaroor diere wel beskik en wat vir die gelowige van belang is, en erken behoort te word, is die volgende:

- Die reg op lewe en instandhouding daarvan wat impliseer dat die dier ten minste geregtig is op voedsel, versorging en beskerming.

- Die reg op vryheid van beweging en assossiasie. Diere kan alleen tot eer van God leef as hulle toegelaat word om vry te beweeg in hul natuurlike habitat en te assosieer met die spesie waarvan hulle op natuurlike wyse deel vorm.

Wanneer hierdie regte ontken word, word diere onreg angedoen. Ongeregtigheid teenoor enige van God se skepsels is teenstrydig met 'n Christelike lewenswyse. Jones (1992:220-221) gee die volgende voorbeelde van hoe hierdie regte in prakyk misken word: Wanneer 'n dier voedsel ontneem word, mishandel word, na willekeur in eksperimente vir mediese doeleindes gebruik word, gebruik word om in die rekreasie behoeftes van die mens te voorsien soos stier-, honde-, en ander gevegte, uitwissing deur onverantwoordlike jag, oorbodige uitslagting om in die voedselbehoeftes van die mens te voorsien, diere wat onder dwang onder moeilike en pynlike omstandighede vir produksiedoeleindes aangehou word, die dikwels onsensitiewe wyse waarop diere doodgemaak word, onbillike en onregverdige beheer van diere, en die inperkende wyse 
waarop eksotiese en ander diere aangehou word. Jones is van mening dat waar die verhouding tussen mens en dier op hierdie wyse versteur word, diere se onveranderlike skeppingswaarde wat aan hulle sekere regte verseker, van hulle ontneem word en dat die teologiese etiek 'n uitspraak daaroor moet lewer. Die teologie kan dus riglyne vir gedrag daarstel om positiewe mens-dier interaksie te bevorder.

In 'n ondersoek deur Herzog (1993:117-118) is bevind dat daar 'n verband tussen mense se betrokkenheid by diereregte en hulle fundamentele geloofsoortuigings, verandering in lewenstyl, 'n evangelisasie motief, skuldgevoelens, en die navolging van die werk en lewe van Jesus Christus bestaan (vgl Cobb 1993:172-173; Sutherland 1994:171186). Dit blyk dus dat daar wel 'n verband tussen godsdienstigheid en positiewe mensdier interaksie is. 'n Verandering in lewenstyl, of "life style correctness" soos Leichter (1997:359) daarna verwys, ten opsigte van al die dimensies van menswees behoort egter die fokus te wees.

Die regte van mense en díe van diere word dikwels teenoormekaar gestel, met mekaar vergelyk en/of vanuit uiteenlopende filosofiese benaderings verdedig. Die vraag is egter of regte enigsins spesiegebonde kan wees? Sowel Clark (1997:9) as Bowd \& Shapiro (1993:136) spreek hulle teen so 'n vergelyking uit en is van mening dat om etiese besluite te neem op grond van lidmaatskap aan 'n spesifieke spesie, sonder inagneming van ander veranderlikes, net so arbitrêr is as om velkleur, geslag of verstandelike of fisiese vermoëns as maatstaf vir waarde te gebruik. Etiese vrae rondom mens-dier interaksie hou dus verband met watter maatstaf gebruik word. Is dit ekonomies, simbolies, sielkundig, emosioneel, kultureel, ekologies, terapeuties of geestelik? (Watter maatstaf word gebruik om die waarde van mense te bepaal?) 'n Objektiewe antwoord op hierdie vraag is onwaarskynklik. Binne elke groepering van mense sal goed gemotiveerde argumente ter stawing van hulle eie maatstawwe gebruik word. Diskriminasie in enige vorm en teenoor enige iemand (wat diere insluit) is egter vanuit 'n teologiese perspektief oneties.

Dit wil dus voorkom of daar in die nadering na die $21^{\mathrm{e}}$ eeu 'n groter bewustheid onder teoloë ten opsigte van die intrinsieke waarde van diere is. McDaniel $(1993: 76,87)$ verwys hierna as "creation-inclusive theologies" en interpreteer dit dat die liefde van God nie onderling uitsluitend is nie en dus ook liefde vir diere, en tussen mens en dier, insluit. 
Hierdie liefde behoort in die gemeenskap van gelowiges waargeneem te kan word. McDaniel (1993:95) gaan verder deur te sê dat 'n Christelike gemeenskap onder andere gekenmerk word (of behoort te word) deur deelname, verantwoordlikheid en respek vir verskille (vgl Linzey 1994:3). In ons verhouding met diere impliseer dit dat hulle biologiese en sosiale behoeftes in ag geneem word en hulle dus daardeur indirek inspraak het of deelneem aan besluite wat hulle lewens raak, dat verantwoordlikheid geneem word vir hulle algemene gesondheid en welstand en dat waardering bestaan vir hulle unieke kwaliteite en bydrae wat hulle tot die gemeenskap lewer (vgl Linzey \& Cohn-Sherbok 1998:31; Manes 1998:31; Smith 1998:31; Webb 1998:25).

\section{TEN SLOTTE}

Ten spyte van die verandering in denke en teologiese tradisies met betrekking tot mensdier interaksie, het mense se gebruik van diere tot hulle eie voordeel net meer tegnologies gevorderd en die manipulering van etiese vrae net meer verfynd geraak. Swabe (1999:9) voorspel dat, in die oorgang na die $21^{\mathrm{e}}$ eeu, die gebruik van diere stelselmatig sal toeneem en dat die moderne samelewing reeds afhanklik geraak het, maar onbewus is van die omvang, van die eksploitasie van diere. Clugston (1993:232-233) deel hierdie vrees en sê dat ons bewus moet word daarvan dat: “... our dominant values and economic system encourage the abuse of the earth, people, and animal." Om hierdie wanbalans uit die weg te ruim sal insette van verskeie dissiplines betrokke by mens-dier interaksie verg. Verskille in houdings en gedrag word onder andere beïnvloed word deur teologiese en filosofiese uitgangspunte, kulturele waardes, omgewingsfaktore, lewenstyl en lewensomgewing, sosio-ekonomiese faktore, maatskaplike funksionering en opvoedingspeil. Hierdie dinamiese interaksie tussen sisteme gee daartoe aanleiding dat elke individu, groep of gemeenskap uniek is in hulle definisie van positiewe mens-dier interaksie.

Die teoloog kan nietemin 'n belangrike bydrae lewer om mense se houdings en gedrag teenoor diere positief te beïnvloed deur die boodskap van liefde vir en verantwoordelikheid teenoor die skepping uit te dra. Deur middel van die prediking, Bybelstudie, kategese, huisbesoek en ander gemeentebyeenkomste, kan geleenthede doelbewus benut en geskep word om mense meer bewus te maak van hulle rol in die bevordering van positiewe mens-dier interaksie. 'n Leemte bestaan voorts op die gebied 
van multidissiplinêre navorsing en opleiding, waarby die teologie betrek word, in die studieveld.

\section{Literatuurverwysings}

Animal Voice 2000. January-April \& September-December Editions. Humane Education Trust. South Africa: Somerset West.

Aydin, M 1998. Human-animal relationship: An Islamic perspective. Paper presented at the $8^{\text {th }}$ International conference on human-animal interactions, 10-12 September, Prague.

Bowd, A D \& Shapiro, K J 1993. The case against laboratory animal research in Psychology. Journal of Social Issues 49(1), 133-142.

Clark, S R L 1997. Animals and their moral standing. London: Routledge.

Clugston, R M 1993. The state of the animals: Human impact on wild and domestic animals, in Pinches, C \& McDaniel, J B (eds), Good news for animals? Christian approaches to animal well-being. New York: Orbis Books.

Clutton-Brock, J.1994. The unnatural world: Behavioural aspects of humans and animals in the process of domestication, in Manning, A \& Serpell, J (eds), Animals and human society. London: Routledge.

Cobb, J B (Jr) 1993. Economics for animals as well as people, in Pinches, C \& McDaniel, J B (eds), Good news for animals? Christian approaches to animal well-being. New York: Orbis Books.

Cohen, E 1994. Animals in medieval perceptions: The image of the ubiquitous other, in Manning, A \& Serpell, J (eds), Animals and human society. London: Routledge.

Figle, J 1998. The human animal relationship in world religions. Paper presented at the $8^{\text {th }}$ International conference on human-animal interactions, 10-12 September, Prague.

Fogle, B 1999. The changing roles of animals in Western society: Influences upon and from the veterinary profession. Anthrozoös 12(4), 234-239.

Frear, G L (Jr) 1993. Caring for animals: Biblical stimulus for ethical reflection, in Pinches, C \& McDaniel, J B (eds), Good news for animals? Christian approaches to animal well-being. New York: Orbis Books. 
French, W C 1993. Beast - machines and the technocratic reduction of life: A creationcentered perspective, in Pinches, C \& McDaniel, J B (eds), Good news for animals? Christian approaches to animal well-being. New York: Orbis Books.

Hauerwas, S \& Berkman, J 1993. A trinitarian theology of the "chief end" of "all flesh", in Pinches, C \& McDaniel, J B (eds), Good news for animals? Christian approaches to animal well-being. New York: Orbis Books.

Herzog, H A Jr 1993. "The movement is my life": The psychology of animal rights activism. Journal of Social Issues 49(1), 103-119.

Hume, C W 1980. The status of animals in the Christian religion. London: The Garden City Press.

Hung, W 1998. The Buddhist perspective on animals and life conservation: Their changing roles in society. Paper presented at the $8^{\text {th }}$ International conference on human-animal interactions, 10-12 September, Prague.

Jones, C 1992. 'n Teologies-etiese studie van menseregte met 'n toepassing op die situasie in Suid-Afrika. DD-proefskrif, Universiteit van Suid-Afrika.

Jung, L S 1993. Animals in Christian perspective: Strangers, friends or kin?, in Pinches, C \& McDaniel, J B (eds), Good news for animals? Christian approaches to animal well-being. New York: Orbis Books.

Leichter, H M 1997. Lifestyle correctness and the new secular morality, in Brandt., A M \& Rozin, P (eds), Morality \& health. London: Routledge.

Linzey, A 1994. Animal theology. London: SCM.

Linzey, A \& Cohn-Sherbok, D 1998. After Noah: Animals and the liberation of theology. Human \& Other species (2),31.

Maehle, A-H 1994. Cruelty and kindness to the "brute creation": Stability and change in the ethics of the man-animal relationhip, 1600-1850, in Manning, A \& Serpell, J (eds), Animals and human society. London: Routledge.

Manes, C 1998. Other creations: rediscovering the spirituality of animals. Humans \& Other species 2, 31 .

Manning, A \& Serpell, J (eds) 1994. Animals and human society. London: Routledge.

McDaniel, J B 1993. A God who loves animals and a church that does the same, in Pinches, C \& McDaniel, J B (eds), Good news for animals? Christian approaches to animal well-being. New York: Orbis Books. 
Newby, J 1997. The pact for survival: Humans and their companions. Sydney: ABC Books.

Odendaal, J S J \& Meintjes, R A 1999. A physiological basis for positive humancompanion animal interaction. Proceedings of the $2^{\text {nd }}$ International congress on veterinary ethology, Lyon, France.

Palmer, M \& Breuilly, E 1996. After the ark: Religious understandings of ourselves and other animals. London: Forbes Publications.

Plous, S 1993. Psychological mechanisms in the human use of animals. Journal of Social Issues 49(1), 11-52.

Rogers, L 1995. Do animals think?, in Bakeer, R M, Einstein, R, Mellor, D J \& Rose, M A (eds), Animals and science in the twenty-first century: New technologies and challenges. Proceedings of the conference held at the Business School, University of Melbourne, 7-8 October, 1994.

Ruether, R R 1993. Men, women, and beasts: Relations to animals in Western culture, in Pinches, C \& McDaniel, J B (eds), Good news for animals? Christian approaches to animal well-being. New York: Orbis Books.

Smith, S S 1998. Pet souls: Evidence that animals survive death. Humans \& Other Species 2, 31 .

Sutherland, A \& Nash, J E 1994. Animal rights as a new environmental cosmology. Qualitative Sociology 17(2), 171-186.

Swabe, J 1999. Animals, disease and human society: Human-animal relations and the rise of veterinary medicine. London: Routledge.

Turner, D C 1996. Ethical issues in companion animal ownership, use and research, in Nicholson, J \& Podberscek, A (eds), Further issues in research in companion animal studies. Proceedings of a workshop held at the University of Cambridge by the Society for Companion Animal Studies (SCAS).

Watson, D 1998. The spirituality of animals: A Christian perpective. Paper presented at the $8^{\text {th }}$ International conference on human-animal interactions, 10-12 September, Prague.

Webb, S H 1998. On God and dogs: A Christian theology of compassion for animals. Humans \& Other Species 4, 25. 